\title{
Students' Perceptions of School-Related Conditions Impacting Their Motivation and Engagement in Learning
}

\author{
Kumbukage Dona Ruwandika Lakmali Jayalath Perera \\ Department of Secondary and Tertiary Education, Faculty of Education, The Open University of Sri Lanka, \\ Nugegoda, Sri Lanka \\ Email: kdper@ou.ac.lk
}

How to cite this paper: Perera, K. D. R. L. J. (2021). Students' Perceptions of SchoolRelated Conditions Impacting Their Motivation and Engagement in Learning. Open Journal of Social Sciences, 9, 353-377. https://doi.org/10.4236/jss.2021.99025

Received: August 20, 2021

Accepted: September 13, 2021

Published: September 16, 2021

Copyright (๑) 2021 by author(s) and Scientific Research Publishing Inc. This work is licensed under the Creative Commons Attribution International License (CC BY 4.0).

http://creativecommons.org/licenses/by/4.0/ (c) (i) Open Access

\begin{abstract}
The data and information show that student participation in junior secondary schools in Sri Lanka, particularly in low socio-economic districts is considerably low. There are many reasons behind this. It seems that students' low motivation and engagement might be one of the reasons. One of the problems for that might be school-related conditions. Therefore, this study investigated the perceptions of students regarding school-related conditions impacting their motivation and engagement in learning. Self-determination theory to understand students' intrinsic motivation was used as the theoretical base of this study. This study employed explanatory sequential mixed methods research design. Data were gathered from seven Tamil medium and five Sinhala medium type, two government schools located in the Monaragala and Nuwara Eliya districts. At the first phase (quantitative) of the study, the Motivation and Engagement Scale-Junior School was administered among two hundred grade, eight students and at the second phase (qualitative) of the study according to the scale scores, 12 male and 12 female students, identified as least motivated, were selected to be interviewed. Semi-structured interviews were conducted to collect data from the selected 24 students. The second phase (qualitative) data was used for this study. Thematic analysis was applied for analysing data. Analysis of interviews revealed two main themes in relation to the school-related conditions that impacted students' motivation and engagement in learning: 1) quality of classroom relationships; and 2) quality of curriculum and resources. In theme one, quality of classroom relationships; negative teacher-student relationship and influence of peers were emerged as subthemes. Under the sub-theme, negative teacher-student relationship, four categories were identified: harsh punishments, inadequate encouragement, unengaging teaching, and unfriendly teaching-learning environment. In theme
\end{abstract}


two, quality of curriculum and resources; inadequate quality learning activities, difficult subject matters, difficult and excessive homework, regular tests, inadequate classroom resources, and inadequate quality teaching-learning resources were emerged as sub-themes. It is imperative that the negative schoolrelated conditions impacting students' motivation and engagement should be taken into consideration to increase students' participation in learning.

\section{Keywords}

Engagement in Learning, Intrinsic Motivation, School-Related Conditions, Students' Perceptions

\section{Introduction}

The Sri Lankan Government provides support for students at all levels of the school system, for example, free education, textbooks, school uniforms, subsidised public transportation, and school meals. However, low participation in learning among secondary students is an issue warranting investigation, particularly in low socio-economic areas in Sri Lanka. The Central Bank of Sri Lanka (2015, 2016), Ministry of Education (2011, 2014) and Ministry of Education, UNICEF, and MG Consultants (2009) suggest that this trend will continue unless schools radically shift their educational approaches and support for junior secondary students. One of the main factors affecting for this situation might be the school-related conditions. This study investigated students' perceptions about school-related conditions impacting their motivation and engagement in learning in low socio-economic districts in Sri Lanka.

Liyanage (2013) emphasised that even though Sri Lanka is considered a South Asian country with a high literacy rate, the situation hides many serious weaknesses in its education system. There have been several issues related to the Sri Lankan education system, such as low participation and low attendance; low achievement in mathematics and science; imbalanced allocation of resources among schools, particularly between urban and rural schools; and an excessively large curriculum etc. Little, Indika, and Rolleston (2011) identified several inequalities regarding secondary education enrolment that need to be addressed to achieve this, including disparities between male and female students, urban and rural schools, and among school types and income groups.

While Sri Lanka has universal compulsory education for all children between five and 14, in practice not all students attend school (World Bank, 2005). According to this report about $18 \%$ of students are unable to complete grade 9 . Many of these children come from deprived homes, economically deprived geographical areas, including the estate sector, and areas that are remote, and war affected. The Millennium Development Goals Country Report (United Nations, 2014) affirmed that the percentage of children attending school after age 14 is lower for males than females; this is mainly the case in the rural and estate sec- 
tors.

According to Perera (2011) poor teacher-student relationships and lack of teachers' attention have been factors for poor retention in school. She has identified that negative teacher-student relationships, negative peer groups, and an unfriendly classroom and school environment as factors reduce the desire of students to attend school (Perera, 2006).

Jayaweera and Gunawardena (2013) conducted a study on children who are not attending school, accordingly most out-of-school students were in the 10 to 14 age group. The out-of-school children percentage was comparatively higher in the Sri Lankan Tamil population.

The above data and information show that student participation in junior secondary school in Sri Lanka, particularly in low socio-economic districts is considerably low. There are many reasons behind this. According to the literature review, it seems that the school-related conditions are very important for students' motivation and engagement in learning. The selected low socio-economic districts students also might face these school-related conditions in their learning. Therefore, those conditions might have negative impact for their intrinsic motivation and engagement in learning. It is important to reveal the school-related conditions impact for this group of students' motivation and engagement in learning. Therefore, this study investigated the perceptions of students regarding school-related conditions impacting their motivation and engagement in learning in selected two low socio-economic districts in Sri Lanka.

Specific objective of the research study was to examine the students' perceptions about school-related conditions impacting motivation and engagement in learning.

\section{Literature Review}

Several constructs have been identified that impact persistence, retention, and academic success. These constructs include self-efficacy, motivation, and engagement (Aji \& Khan, 2019: p. 205). There might be various school-related conditions impacting students' motivation and engagement in learning.

Symonds and Hargreaves (2016) highlight that school transition is a noteworthy life experience for many early adolescents. Though this factor is not directly linked to the Sri Lankan educational context, when understanding global trends about early adolescents' motivation and engagement, reviewing this factor is important. In the USA, UK and other parts of Europe, adolescents' feelings about their school and the importance they give to the school decreases upon transition to secondary school (Stroet, Opdenakker, \& Minnaert, 2013; Symonds \& Galton, 2014). According to stage-environment fit theory (Eccles \& Midgley, 1989), this occurs because of a disparity between their developmental needs and new school conditions. After school transition, there is a tendency for a declining relationship with teachers while, the relationship with peers increases (Symonds \& Galton, 2014). Moreover, during transition, students exhibited a stronger rela- 
tionship between the school environment and their self-concept (Symonds \& Hargreaves, 2016).

Student-teacher relatedness is important in any educational context when deciding students' motivation and engagement in learning. It is a state that learners should reach, and teachers or instructors should help their learners to achieve. One of the tools to achieve an engaged state, a most essential one we might add, is student motivation.

(Kanellopoulou \& Giannakoulopoulos, 2020). Most research investigating the ways in which teachers maintain student motivation has been based on a single perspective (Schmakel, 2008) using quantitative or observational methods. Roorda, Koomen, Spilt and Oort (2011) carried out a meta-analysis of the impact of teacher-student relationships on student engagement and achievement. Those findings showed that student motivation was improved if the teacher-student connection was excellent, particularly for in-danger, low socio-economic young people. According to Ryan and Patrick (2001) and Schmakel (2008), teachers play a very important role in promoting adolescents' educational motivation. However, as emphasised by Eccles and Roeser (2011), many adolescents do not experience that kind of interesting teaching practice. This situation can result in a disparity among young adolescent experiences and impact on their fundamental and developmental needs.

Research (Knesting, 2008; Wilson, 2007) suggests that caring teachers and highly regarded relationships lead to students being engaged in their learning, performing at high levels, and remaining in school. Furthermore Rhodes, Grossman and Resch (2000) stated that relationships with teachers are especially significant to early adolescents who frequently experience changes in their feeling of self and are stressed by their developing relations with parents and peers. As found by Goodenow (1993), students were engaged in class when they perceived strong support from their teachers. However, Hardre and Sullivan (2009) found that nearly all teachers believe they can influence student learning, but they are doubtful about their ability to control students' motivation.

The global literature on students' motivation and engagement indicates that peer relationships are important. Azmitia (2002) notes that for early adolescents, friendships can give a sense of belonging and contribute to their overall identity. In addition, Wang and Eccles (2013) showed that students with positive peer relationships are more behaviourally and emotionally engaged at school.

There are many studies on the impact of peer relationships on educational motivation and adjustment as pupils' transition to middle school (Nelson \& Debacker, 2008; Wang \& Eccles, 2013). Nelson and Debacker (2008) investigated connections between perceived student relationships and achievement motivation in middle school science classes. Their study examined, among other factors, how students' sense of the peer environment and belongingness in the classroom might impact performance-related goals and self-efficacy. In summary, the researchers reported that class relatedness had a large influence on the motivation to learn and those students who thought they were appreciated in the classroom 
showed higher levels of self-efficacy and proficiency.

The research literature indicates that motivation and engagement are possible predictors of students' academic achievement. As reported by Lamb, Walstab, Teese, Vickers, and Rumberger (2004), academic achievement plays a major role in the decision to leave school; the relationship between poor educational performance and leaving school is widely reported in the global literature (e.g., Alexander, Entwisle, \& Olsen, 2001).

Williams (2000), who conducted a large cross-sectional study, found that student engagement influences differences in student achievement in school and classroom settings. Thus, student engagement is a possible predictor of student achievement in a variety of ways (Walker, Greene, \& Mansell, 2006). Motivation is also crucial to the success of a college student in terms of academic achievement and future accomplishments (Salinas-Jimenez, Artes, \& Salinas-Jimenez, 2010). Students who are more intrinsically motivated have been found to exhibit better outcomes in academic achievement (Di Domenico \& Fournier, 2015).

Some research (e.g., Eccles \& Wigfield, 2002) reveals that motivation becomes more differentiated over school subjects by age, with students gradually becoming more motivated to learn subjects in which they are successful. Gottfried (1990) conducted a longitudinal study of students' motivation and achievement in reading and mathematics and found that motivation for learning mathematics was predicted by previous mathematics achievement and motivation.

Moreover, a study of 1125 Year 9 and 10 students in Queensland (Australia) secondary schools exposed that a deficiency in curriculum subject choices in the lower secondary school causes disappointment in some students who worry that the secondary school will not be able to prepare them for the job training they seek (Pitman \& Herschel, 2002). Lamb, Dwyer, and Wyn (2000) found that a considerable number of premature leavers reported that the key reason for departing school was not providing follow-up study courses by the school.

Accordingly, it is evident that school-related conditions, such as school transition, teacher-student relatedness, peer relationships, academic achievement in school, and curriculum are impacted for students' intrinsic motivation and engagement in learning.

\section{Methodology}

This study employed explanatory sequential mixed methods research design. Specific objective of the research study was:

To examine the students' perceptions about school-related conditions impacting motivation and engagement in learning.

The Motivation and Engagement Scale-Junior School (Martin, 2014) was administered among two hundred grade eight students at the first phase (quantitative) and at the second phase (qualitative) of the study according to the scale scores, 12 male and 12 female students, identified as least motivated, were selected to be interviewed. Data was collected from the selected 24 students. The second phase (qualitative) data was used for this study. 
Self-determination theory to understand students' intrinsic motivation was used as the theoretical framework of this study. Students who were studying in the eighth grade in the selected schools were included in the target population. Data were gathered from seven Tamil medium and five Sinhala medium type two government schools located in the Monaragala and Nuwara Eliya districts, which are considered as low socio-economic districts in Sri Lanka. According to the scale scores, twelve male and twelve female students, identified as least motivated, were selected to be interviewed using the purposive sampling method (Table 1).

In this research, students were asked questions relating to the school-related conditions impacting students' motivation and engagement using semi-structured interviews. As per the nature of this study, the semi-structured interview method was considered the most suitable interview technique. Using this method, the researcher was able to record a considerable number of views of respondents regarding the problem of the research.

To analyse data thematic analysis was employed as the technique for recognising themes and patterns of meanings pertaining to students' opinions and experiences in relation to the school-related conditions impacting their motivation and engagement in learning. In summary, a data driven (inductive) and semantic approach was employed for thematic analysis in this study. The deciding factors in selecting thematic analysis for the qualitative data analysis method for this research study was its flexibility, its ease of use, its ability to highlight similarities and differences across the dataset, and its ability to offer a detailed, rich, and compound description of the semi-structured interviews.

\section{Results and Discussion}

The thematic analysis conducted for the responses of twenty-four students semistructured interviews revealed two main themes in relation to the school-related conditions that impacted students' motivation and engagement in learning: quality of classroom relationships and quality of curriculum and resources. It should be noted that statistical analysis was not taken place in this qualitative phase of the study.

\subsection{Quality of Classroom Relationships}

Within the quality of classroom relationships' theme, a further two sub-themes emerged: negative teacher-student relationship, and influence of peers.

Table 1. Sample chosen for conducting interviews.

\begin{tabular}{cccc}
\hline District & No. of schools & \multicolumn{2}{c}{ No. of students } \\
\cline { 3 - 4 } & & Male & Female \\
\hline Monaragala (Sinhala-medium) & 7 & 7 & 7 \\
Nuwara Eliya (Tamil-medium) & 5 & 5 & 5 \\
Total & 12 & 12 & 12 \\
\hline
\end{tabular}




\subsubsection{Negative Teacher-Student Relationship}

Interviewed students' responses revealed there was a negative impact of the teacher-student relationship for students who identified as having low motivation and engagement in learning. Under this sub-theme, four categories emerged: harsh punishments, inadequate encouragement, un-engaging teaching, and unfriendly teaching-learning environment.

\section{Harsh Punishments}

Even though the law in Sri Lanka prohibits corporal punishment in schools, it is still practiced in schools. The findings of this study revealed that most students reported that most of their teachers administered harsh punishments to them for not performing well. This was particularly true for male students; they noted this was the reason they hated school (Appendix A-1).

Some students scoring low marks reported facing verbal threats from teachers. The participants agreed that teachers threatened their self-esteem. Most of the male students interviewed mentioned that being openly scolded by teachers in front of the class caused them severe embarrassment. Students noted how an unkind teacher would frequently become angry with the whole class for something that only a small number of students had done. Students considered this as unjust because it deprived them of time that could have been spent on class work.

In relation to ethnicity, both Sinhala and Tamil-medium students were given harsh punishments by their teachers for non-completion or bad performance in learning activities. Some Sinhala-medium students stated that their teachers were very tough, not friendly, and some teachers punished them for each wrong answer (Appendix A-1).

Jayaweera and Gunawardena (2013) found that children reported that high absenteeism was linked to harsh punishment given in school in Sri Lanka. Jayaweera and Gunawardena (2009) found that punishment of students by teachers was very high in Type $1 \mathrm{AB}$ (schools having GCE $(\mathrm{A} / \mathrm{L})$ with all the subject streams (Grade 1 - 13) and 1C (schools having GCE (A/L) Arts/Commerce streams only/No Science stream (Grade 1 - 13) schools. However, this study sample consisted of Type 2 schools (schools having classes Grade 1 - 11). The types of punishment described by students included corporal punishment. Wagle (2012) found that corporal punishment was one of the school-related problems that forced students to leave school early. In addition, Ministry of Education, UNICEF, and MG Consultants (2009) found that teachers regularly punished students and that they did not attempt to recognise the learning hardships or the personal problems of children and identified these as probable causes of early dropout. The findings of the current study supported the findings of the previous research.

Reeve and Jang (2006) argued that controlling language, such as commands, decreases autonomy in students. Similarly, Vansteenkiste, Lens, and Deci (2006) indicated that using guilt-inducing language as a control mechanism creates internal pressure. Niemiec and Ryan (2009) proposed that teachers could use strategies to enhance relatedness by passing on kindness, being thoughtful and valuing 
students.

At the controlled or non-autonomous end of this continuum is external regulation in which a person's actions are compelled or driven by externally controlled rewards or punishments. Here the behaviour is fuelled by the contingencies of reinforcement and punishment (Ryan, Williams, Patrick, \& Deci, 2009: p. 112).

Reeve, Deci, and Ryan (2004) found in their study that students' levels of engagement could be increased by using non-controlling language as measured by active task involvement and attempts to take responsibility for their learning; that is making many of the learning tasks in schools intrinsically motivating. An essential concern is how to motivate students to self-regulate and value those tasks (Ryan \& Deci, 2000b).

In sum, student comments in the interviews indicate that the students receive harsh punishments from some of their teachers and, which possibly explains their decreased intrinsic motivation and engagement in learning.

\section{Inadequate Encouragement}

Most interviewed students claimed they were not appreciated by teachers, very few noted encouragements. The students did not indicate a lack of encouragement based on gender or ethnicity difference. They expected encouragement from teacher even for smaller attempts (Appendix A-2).

Reeve and Jang (2006) argue that teachers can use praise to foster improvement, encourage effort, offer hints to students to boost progress, and be responsive to students' perspectives to increase students' perceptions of autonomy. Elliot, Faler, and McGregor (2000) states that positive, constructive performance feedback that encourages development facilitates internalisation of self-regulation.

Teachers should provide students with suitable tools and encourage them to accomplish their learning goals. A predominant view is that students will only connect and individually value activities they can comprehend and in which they can be proficient (Niemiec \& Ryan, 2009). Moreover, it is possible that teachers are more attentive to students who demonstrate concentration during the lesson and provide those students with more constructive feedback, and, therefore, those teachers are regarded by the students as being autonomy-supportive (Tsai, Kunter, Lüdtke, Trautwein, \& Ryan, 2008). It appears that the students in this study do not get that kind of encouragement from their teachers, and these conditions undermine the natural process of self-determination and psychological well-being.

It was revealed that most of the students interviewed did not get enough encouragement from their teachers. And their intrinsic motivation and engagement in learning might have negatively impacted.

\section{Un-engaging Teaching}

Almost all the students in the interviewed sample mentioned that their teachers approach to teaching was not motivating. Students reported their teachers spent the majority of class time talking to the class (teacher-focused direct instruction) with little student participation. According to them there are no new activities. 
And teachers used traditional teaching methods and techniques. (Appendix A3).

Apparently, the teachers referred to did not use innovative teaching aids. This is linked to the section comments under the heading "Inadequate quality learning activities". Williams and Williams (2011) state that the five key elements affecting student motivation are: student, teacher, content, method/process, and atmosphere. The method or process must be creative, reassuring, motivating, valuable and give tools that can be functional in the students' lives. Moreover, $\mathrm{Ku}-$ surkar, Croiset, and Ten Cate (2011) argue that teachers should pay patient attention to students and empathise with them when they convey their lack of interest or displeasure with an exacting topic or an exacting technique of teaching. If the teacher refuses to accept negative thoughts from the students, the students tend to drop all concentration in the following lessons. Students need to feel that they are being listened to, that their thoughts are significant to the teacher, and that they can make an impact on elements of the lessons with their positive comment. It is vital not to judge when students express their thoughts.

Granito and Chernobilsky (2012) stated that students react confidently to technology and sometimes are frustrated by technology; teachers should make a conscious effort to plan activities that include some form of technological device. Thus, teachers should use different innovative teaching aids as much as possible because motivated students tend to achieve at their maximum levels, making the most of the opportunities their teachers provide. If students find their schoolwork interesting, their competence and relatedness with their teacher and peers might increase, and thus their self-determination in learning will also increase.

According to the students' responses, it seems that these teachers have not engaged in teaching properly, which lead to reduce students' low motivation and engagement in learning.

\section{Unfriendly Teaching-Learning Environment}

The responses of interviewed students from both school groups indicated that they encountered unfriendly (not caring) classroom environments. This was particularly true of the male and Tamil-medium students (Appendix A-4). According to them teachers did not care about them.

This situation might have evolved because of the many untrained and unqualified teachers in Tamil schools. Further, some male students interviewed mentioned that some teachers do not listen to their input and attempt to control their behaviour. Grabau (1999) argued it is important to value and respect students. Also, Fenty (1997) emphasised that understanding students and the challenges they are facing at the same time as learning, increases retention rates and the general achievement of students. Wagle (2012) conducted a study on school-related problems and found lack of teaching-learning behaviour in the lessons as one of the noticeable school-related problems that led to students leaving school early. In addition, Sagor (2003) pointed out that in respectful classrooms, teachers planned lessons that gave opportunities for students with varied learning styles, intelligence, and cultural differences. Further, teachers created an atmosphere of 
mutual respect by preventing students from making fun of others, encouraging students to value the contributions of others, and requiring students to be considerate of the feelings of others (Patrick, Ryan, \& Kaplan, 2007). According to Niemiec and Ryan (2009), a feeling of belonging is closely linked with intrinsic motivation and a student's sense that she/he is liked, admired, and valued by the teacher.

Research (Knesting, 2008; Wilson, 2007) suggests that caring teachers and highly regarded relationships are linked to students becoming engaged in their learning, performing at high levels, and remaining in school. Furthermore Rhodes, Grossman, and Resch (2000) stated that relationships with teachers are especially important for students who frequently experience changes in their sense of self and struggle with their growing relationships with parents and peers.

Accordingly, these students have experienced unfriendly teaching-learning environment in their schools. Therefore, their intrinsic motivation and engagement in learning might be reduced.

\subsubsection{Influence of Peers}

Some interviewed students said that they lacked motivation and engagement in learning because of poor peer relationships. It seems that most of the peers in their classrooms were not motivated and engaged in learning. They did not value the education. This was particularly true for male students (Appendix A-5).

Wang and Eccles (2013) stated that studies show that students with positive peer relationships are more behaviourally and emotionally engaged at school; this is particularly the case for adjustment to middle school across the transition (Nelson \& Debacker, 2008; Wang \& Eccles, 2013). Kingery, Erdley, and Marshall (2011) measured peer acceptance and friendship quality in relation to predicting adjustment across the transition to middle school and found that both these factors play a significant role in student loneliness and school involvement.

Fried and Konza (2013) believe that teachers should think about peer relations when preparing learning activities. Peer interaction gives students a better chance of increasing their sense of relatedness. Belonging refers to the sense of association with other people, a sense that comprises a feeling of being integrated with and respected by other people in the learning environment (Ryan et al., 2009). The interview results show that these least motivated students did not feel sufficiently positively integrated with their peers. This is particularly evident from the response given by S 10 in the quote above. Since, peers are not motivated they also feel unmotivated; motivation to learn might be transferred from one student to another.

It was revealed that poor peer relationships have negatively impacted for these students' intrinsic motivation and engagement in learning.

\subsection{Quality of Curriculum and Resources}

Under the main theme of quality of curriculum and resources, six sub-themes emerged: inadequate quality learning activities, difficult subject matters, difficult 
and excessive homework, regular tests, inadequate classroom resources, and inadequate quality teaching-learning resources.

\section{Inadequate Quality Learning Activities}

Students interviewed mentioned that they did not have quality learning activities to pursue within their classrooms. Low quality learning activities lead to a low level of intellectual challenge. This sentiment was expressed by male students' more than female students. It seems that there were limited learning activities and those were also not innovative and challenging (Appendix A-6).

There was no notable difference among the responses in relation to ethnicity. Students were often reluctant to participate in classroom interactions for fear of giving wrong answers and/or being laughed at by peers. By planning group work, teachers can foster a supportive community in the classroom and provide the less confident students with a less threatening situation (Hinde-McLeod \& Reynolds, 2007).

Anderman and Leake (2005) suggest that, even if teachers cannot give free reign to their students, providing frequent choices in activities and assignments would increase students' sense of autonomy since people will be intrinsically motivated to carry out tasks in which they have an inherent interest or tasks that are innovative, challenging or have artistic value (Ryan \& Deci, 2000b). In other words, activities that are not intellectually challenging diminish students' motivation.

For activities that are not intellectually challenging, the principles of SDT do not apply. Legault, Pelletier, and Green-Demers (2006) indicated that students' autonomy could be increased by providing opportunities for students to take initiative and by seeking and respecting their opinions. Encouraging students to take accountability for their own learning does not mean that teachers abandon their students completely to their own plans; the nurturing of autonomy still needs structure and direction but must allow students to take responsibility. Eccles and Roeser (2011) reported that many young adolescents do not sense that type of teaching practices. This situation might affect young adolescents in different ways depending on their school experiences and fundamental and developmental needs.

By providing opportunities for student group work, their sense of relatedness is increased. Providing opportunities to connect with others increases relatedness (Legault et al., 2006). According to Deci, Vallerand, Pelletier, and Ryan (1991), support for relatedness involves enhancing chances for peer acceptance. Moreover, incorporating activities that create opportunities for students to work with their peers, such as cooperative learning will increase students' sense of belonging (Anderman \& Leake, 2005). If a task is usual boring, and regarded as unimportant, amotivation results (Legault et al., 2006). Thus, as Ames (1992) stated, to increase the internalisation process, the task design should highlight the meaning or relevance of the activity. Accordingly, teachers can create personal meaning in activities by understanding students' interests. Engagement is improved by offering activities which are relevant to students' lives, and are experienced as 
attractive and vital (Deci, 2009).

In this study, most male students stated that they did not get quality learning activities during their school time, and both Sinhala and Tamil-medium students gave similar responses. It is evident that the least motivated students do not feel that they get sufficient quality learning activities in their classrooms. This situation is linked with inadequate classroom resources, inadequate quality teachinglearning resources, and lack of quality teaching. This will be discussed later. Lack of quality learning activities may then be responsible for a reduction in their authentic learning and their autonomy, competence, and relatedness, and, thus, it may cause a reduction in their intrinsic motivation towards learning.

Accordingly, these students have not experienced quality learning activities in their teaching-learning process and thus low intrinsic motivation and engagement in learning.

\section{Difficult Subject Matters}

Almost all the students interviewed reported that they had numerous difficulties with several subjects, particularly mathematics, science, and English. Sri Lanka's national curriculum is considered unsuited for the diversity of students and generally accommodates to the most capable students (World Bank, 2011). Most students reported frustrations with the curriculum. They had lots of pressure from difficult subjects, and they were not interested in those subjects. (Appendix A-7).

According to the teachers' and principals' responses, most of the schools surveyed did not have qualified teachers for mathematics, science, and English, particularly in the Tamil schools. Balasooriya (2012) and the World Bank (2011) found that rural schools, including estate schools, find it particularly difficult to recruit and retain teachers in English, science, and mathematics. Moreover, Ministry of Education et al. (2009) identified overloading of the school curriculum as one of the factors contributing to dropout. In addition, Jayaweera and Gunawardena (2013) found that lack of teachers for several subjects was one of the school factors likely to lead to dropout. Arunatilake (2006) also attributed the lower percentages of Sri Lankan Tamil, Indian Tamil and Muslim students participating in education compared to Sinhalese students to teacher shortages in Tamil-medium schools.

Eccles and Wigfield (2002) stated that students made more effort on tasks in which they do extremely well, suggesting that they will be more motivated to study subjects in which they gain a feeling of achievement. Gottfried (1990) conducted a longitudinal study of students' motivation and achievement in mathematics and reading. Motivation for studying mathematics was found to be largely predicted by previous achievement. Further Latif, Choudhary and Hammayun (2015) found pressure of study the most important reason for student dropout in Bangladesh. Students who are excessively controlled not only lose initiative but also do not study well, particularly when studying is difficult (Benware \& Deci, 1984; Grolnick \& Ryan, 1987).

The interviewed students indicated they were not motivated to learn the diffi- 
cult subjects, and neither are they engaged in these subjects. Interview responses also indicated that the curriculum is overloaded. Overall, students' responses suggested they found they could not become competent (master) in those subjects and, thus, their self-determination in learning is diminished.

It could be concluded that, almost all the students interviewed had numerous difficulties with several subjects, particularly mathematics, science, and English which lead for low intrinsic motivation and engagement.

\section{Difficult and Excessive Homework}

Almost all students interviewed expressed a dislike of homework. The general opinion was that the level of homework tasks was far too difficult to enable students to successfully complete them. This was true of the entire student sample, and it was also expressed by the teachers. Also, the students have mentioned that they were getting a lot of homework to do and that was a pressure for them (Appendix A-8).

Most students indicated a frustration with the level, the amount, and the high level of expectations of homework. Katz, Kaplan, and Gueta (2009) conducted a study to investigate students' desires, teachers' assistance, and student motivation for completing homework. They found that teachers' assistance may be more important for students who feel they have a higher level of need. Moreover, teachers' assistance with students' psychological needs was significant for their adaptive motivation for completing homework, regardless of the level of need they expressed.

Students said they had an excessive amount of homework to do and thus they cope less well with homework, and they are demotivated in learning. Research has found that deadlines, directives, and pressured evaluations reduce intrinsic motivation (Ryan \& Deci, 2000b). Similarly, the employment of extrinsic rewards, the burden of closing dates and an emphasis on assessments reduce a sense of self-determination and often lead to diminishing intrinsic motivation (Vansteenkiste, Simons, Lens, Sheldon, \& Deci, 2004). Thus, Anderman and Leake (2005) suggested teachers should teach students how to break the tasks into small sections. When students complete the sections, they see their progress and their confidence increases with each step.

Oginsky (2003) found that giving students a choice in their assignments (a kind of homework) improved intrinsic levels of motivation for middle school students. Suarez (2007) implemented a tiered instructional programme and, as a result, middle school maths students' motivation and performance increased. Students were able to choose which level of assignments they wanted to complete. Suarez labeled the levels green, blue, and black. The green choice was set at a level that exhibited proficiency, and the blue and black represented levels above proficiency. The combination of choosing tasks at their skill level and being able to make decisions in relation to their learning increased the students' responsibility for their learning. Teachers should be able to enhance motivation by having high expectations for completing homework, attendance, behaviour, and educational achievement. Stirring student interest in the classroom whenever possi- 
ble supports autonomy (National Research Council, 2004). However, it seems students in this study did not have the skill and ability to do homework. Nor do they get sufficient motivation from their teachers to complete their homework. Ultimately, that appears to cause a decrease in students' motivation and engagement in learning. This might reflect the high numbers of untrained teachers in low socio-economic districts in Sri Lanka.

It was revealed that almost all students interviewed has dislike of doing homework and it has impacted negatively for their intrinsic motivation and engagement.

\section{Regular Tests}

Most of the students interviewed said they disliked having regular evaluative tests. This applied equally to both gender and ethnic groups. Students expressed that they do not like to have many tests and they were embarrassed in front of peers when getting low marks for them (Appendix A-9).

Niemiec and Ryan (2009) found that in the US and Japan, in real learning settings, evaluative forces decreased, and autonomy support strengthened students' intrinsic motivation for learning. For instance, Tsai et al. (2008) noted that external pressures may elicit a major negative mood in students and influence both their interest and the learning condition in a negative way. Research indicates that high-stakes testing tends to cause teachers to feel less autonomous and, as a result, act in more controlling ways towards students (Roth, Assor, Kanat-Maymon, \& Kaplan, 2007).

Moreover, a student may learn for an examination to get an excellent grade or to avoid being laughed at by peers. This kind of motivation is called external regulation: the smallest amount of the independent type of extrinsic motivation (Niemiec \& Ryan, 2009). According to Williams and Williams (2011), examinations that are more challenging or difficult than work the students have previously encountered in the classroom will have negative impacts on their motivation. Therefore, examinations ought to be based on lesson objectives, and should not surprise students with new concepts or activities.

Results from the interviews indicate that regular evaluative tests diminished students' intrinsic motivation for learning. Interviewed teachers' responses also noted that most of the students in their classes (not only interviewed students) did not attend classes when the monthly tests were held and, if they did, their performance was very low.

It is found that, these students do not like to have regular tests and that will lead for their decrease of intrinsic motivation and engagement.

\section{Inadequate Classroom Resources}

Most interviewed students state that their schools had insufficient classroom resources; this was particularly true for Tamil-medium schools. Therefore, the students did not encounter intellectually challenging learning experiences within their classrooms due to lack of physical resources (Appendix A-10).

Most students complained about merged classrooms and lack of chairs and tables, especially in the Tamil schools. Niemiec and Ryan (2009) stated that learn- 
ing tasks taking place in the classroom increase the perceived competence of students. Thus, in the schools lacking classroom resources for motivational learning activities, such as group work, students were unable to practise and master certain competencies.

Akomolafe and Adesua (2016) emphasised that, if resources are available and carefully utilised to fulfil students' needs, this will always assist students' learning interests and lead to high achievement. It appears that, without having sufficient classroom resources (separated classrooms, chairs, desks, and blackboards, etc.), teachers were unable to provide intellectually challenging learning tasks, and thus increase students' competence towards self-determination in learning.

Most of the interviewed students have experienced inadequate classroom resources in their classrooms, which has impacted for their intrinsic motivation in learning and engagement.

\section{Inadequate Quality Teaching-Learning Resources}

The interview responses of both male and female students suggested that most schools, particularly Tamil schools, did not have sufficient and quality teachinglearning resources. Most of the schools did not have a science laboratory, home science room, library, computer facilities, sports equipment, and musical instruments. Therefore, the students did not encounter intellectually challenging learning experiences in their teaching learning process (Appendix A-11).

Furthermore, insufficient extracurricular activities were provided. Joubish and Khurram (2011) conducted a study to determine the factors influencing dropout rates in government schools of Karachi, Pakistan. They found lack of co-curricular activities as one of the reasons. Chugh (2011) conducted a study on dropout causes in secondary education. She studied dropout rates of children living in Delhi slums attending 33 schools and identified lack of infrastructural facilities in the schools as one of the reasons for dropping out of school early. In addition, Wagle (2012) conducted a study on dropout rates of children from schools in Nepal. The study indicated that school-related problems, such as poor infrastructure, were a noticeable contributor to school dropouts.

Wlodkowski (1999) suggested that teachers could create situational interest by using environmental conditions, such as surprise, novelty, computers, role-playing and simulation, various forms of media, and uncertainty. Ryan and Deci (2000a) note that intrinsic motivation will be stimulated only when tasks are offered that have inherent interest for the person, or that are innovative, courageous, or have artistic importance for the individual. If the physical amenities are accessible, sufficient, and successfully utilised, students' interest can be focused and maintained, leading to high levels of achievement in public secondary school students (Akomolafe \& Adesua, 2016).

The interview data appears to show that the students in this study did not have access to relevant resources for making their learning a quality and an interesting experience, and thus they did not have enough opportunities to become intrinsically motivated and engaged in learning. 


\section{Conclusion}

In relation to the interviewed students' perceptions about how school-related conditions impact upon their motivation and engagement in learning, two main themes emerged: 1) quality of classroom relationships; and 2) quality of curriculum and resources. In theme one, quality of classroom relationships; negative teacher-student relationship and influence of peers emerged as sub-themes. Under the sub-theme, negative teacher-student relationship, four categories were identified: harsh punishments, inadequate encouragement, un-engaging teaching, and unfriendly teaching-learning environment. In theme two, inadequate quality learning activities, difficult subject matters, difficult and excessive homework, regular tests, inadequate classroom resources, and inadequate quality teaching-learning resources emerged as sub-themes. Therefore, it could be concluded that many school-related conditions have negatively impacted for students' motivation and engagement in learning. Thus, to increase the students' participation in learning, those school-related conditions must be taken into consideration. Then those students' motivation particularly intrinsic motivation and engagement in learning will be increased.

\section{Conflicts of Interest}

The author declares no conflicts of interest regarding the publication of this paper.

\section{References}

Aji, C. A., \& Khan, M. J. (2019). The Impact of Active Learning on Students' Academic Performance. Open Journal of Social Sciences, 7, 204-211. https://doi.org/10.4236/jss.2019.73017

Akomolafe, C. O., \& Adesua, V. O. (2016). The Impact of Physical Facilities on Students' Level of Motivation and Academic Performance in Senior Secondary Schools in Southwest Nigeria. Journal of Educational and Practice, 7, 38-42. http://files.eric.ed.gov

Alexander, K. L., Entwisle, D. R., \& Olson, L. S. (2001). Schools, Achievement, and Inequality: A Seasonal Perspective. Educational Evaluation and Policy Analysis, 23, 171-191. http://www.jstor.org https://doi.org/10.3102/01623737023002171

Ames, C. (1992). Classrooms: Goals, Structures, and Student Motivation. Journal of Educational Psychology, 84, 261-271. https://doi.org/10.1037/0022-0663.84.3.261

Anderman, L. H., \& Leake, V. S. (2005). The ABCs of Motivation. The Clearing House, 78, 192-196. http://www.jstor.org

Arunatilake, N. (2006). Education Participation in Sri Lanka: Why All Are Not in School. International Journal of Educational Research, 45, 137-152. https://doi.org/10.1016/j.ijer.2006.11.001

Azmitia, M. (2002). Self, Self-Esteem, Conflicts, and Best Friendships in Early Adolescence. In T. M.Brinthaupt, \& R. P. Lipke (Eds.), Understanding Early Adolescent Self and Identity: Applications and Concepts (pp. 25-56). State University of New York Press.

Balasooriya, B. M. J. (2012). Teacher Recruitment and Teacher Mobility in Sri Lanka, (Commonwealth Education Partnerships 2012/2013, Commonwealth Secretariat). Nexus Strategic Partnerships. 
Benware, C., \& Deci, E. (1984). Quality of Learning with an Active versus Passive Motivational Set. American Educational Research Journal, 21, 755-765.

https://selfdeterminationtheory.org/SDT/documents/1984_BenwareDeci.pdf https://doi.org/10.3102/00028312021004755

Central Bank of Sri Lanka (2015). Annual Report. Central Bank of Sri Lanka.

Central Bank of Sri Lanka (2016). Annual Report. Central Bank of Sri Lanka.

Chugh, S. (2011). Dropout in Secondary Education: A Study of Children Living in Slums of Delhi. National University of Educational Planning and Administration.

Deci, E. L. (2009). Large-Scale School Reform as Viewed from Self-Determination Theory Perspective. Theory and Research in Education, 7, 244-253. https://doi.org/10.1177/1477878509104329

Deci, E., Vallerand, R., Pelletier, L., \& Ryan, R. (1991). Motivation and Education: The Self-Determination Perspective. The Educational Psychologist, 26, 325-346. https://doi.org/10.1207/s15326985ep2603\&4 6

Di Domenico, S. I., \& Fournier, M. A. (2015). Able, Ready, and Willing: Examining the Additive and Interactive Effects of Intelligence, Conscientiousness, and Autonomy Motivation on Undergraduate Academic Performance. Learning and Individual Differences, 40, 156-162. https://doi.org/10.1016/j.lindif.2015.03.016

Eccles, J. S., \& Roeser, R. W. (2011). Schools as Developmental Contexts during Adolescence. Journal of Research on Adolescence, 21, 225-241. https://doi.org/10.1111/j.1532-7795.2010.00725.x

Eccles, J. S., \& Wigfield, A. (2002). Motivational Beliefs, Values, and Goals. Annual Review of Psychology, 53, 109-132. https://doi.org/10.1146/annurev.psych.53.100901.135153

Eccles, J., \& Midgley, C. (1989). Stage/Environment Fit: Developmentally Appropriate Classrooms for Young Adolescents. In R. E. Ames, \& C. Ames (Eds.), Research on Motivation and Education: Goals and Cognitions (Vol. 3, pp. 139-186). Academic Press.

Elliot, A. J., Faler, J., \& McGregor, H. A. (2000). Competence Valuation as a Strategic Intrinsic Motivation Process. Personality and Social Psychology Bulletin, 26, 780-794. https://doi.org/10.1177/0146167200269004

Fenty, J. (1997). Knowing Your Students Better: A Key to Involving First-Year Students. The Centre for Research on Learning and Teaching Occasional Papers, The University of Michigan.

Fried, L. J., \& Konza, D. M. (2013). Using Self-Determination Theory to Investigate Student Engagement in the Classroom. The International Journal of Pedagogy and Curriculum, 19, 27-40. http://ro.ecu.edu.au/ecuworks2013/889 https://doi.org/10.18848/2327-7963/CGP/v19i02/48898

Goodenow, C. (1993). Classroom Belonging among Early Adolescent Students: Relationships to Motivation and Achievement. Journal of Early Adolescence, 13, 21-43. https://doi.org/10.1177/0272431693013001002

Gottfried, A. E. (1990). Academic Intrinsic Motivation in Young Elementary School Children. Journal of Educational Psychology, 82, 525-538. https://doi.org/10.1037/0022-0663.82.3.525

Grabau, L. J. (1999). Respecting Students: Are We Ready for This? Journal of Natural Resources and Life Sciences Education, 28, 104. https://www.agronomy.org https://doi.org/10.2134/jnrlse.1999.0104

Granito, M., \& Chernobilsky, E. (2012). The Effect of Technology on a Student's Motivation and Knowledge Retention. NERA Conference Proceedings. 
http://digitalcommons.uconn.edu

Grolnick, W., \& Ryan, R. (1987). Autonomy in Children's Learning: An Experimental and Individual Difference Investigation. Journal of Personality and Social Psychology, 52, 890898. https://doi.org/10.1037/0022-3514.52.5.890

Hardre, P. L., \& Sullivan, D. W. (2009). Motivating Adolescents: High School Teachers' Perceptions and Classroom Practices. Teacher Development, 13, Issue 1, 1-16. https://doi.org/10.1080/13664530902858469

Hinde-McLeod, J., \& Reynolds, R. (2007). Quality Teaching for Quality Learning: Planning through Reflection. Cengage Learning.

Jayaweera, S., \& Gunawardena, C. (2009). School Participation in Conflict-Affected and Selected Districts in Sri Lanka. Colombo (Unpublished).

Jayaweera, S., \& Gunawardena, C. (2013). Marginalisation and Social Exclusion of Out of School Children in Sri Lanka: Towards Inclusivity. UNICEF.

Joubish, M. F., \& Khurram, M. A. (2011). Determining the Factors Influencing Dropout in Government Primary Schools of Karachi. Middle East Journal of Scientific Research, 7, 417-420. https://www.researchgate.net

Kanellopoulou, C., \& Giannakoulopoulos, A. (2020). Engage and Conquer: An Online Empirical Approach into Whether Intrinsic or Extrinsic Motivation Leads to More Enhanced Students' Engagement. Creative Education, 11, 143-165.

https://doi.org/10.4236/ce.2020.112011

Katz, I., Kaplan, A., \& Gueta, G. (2009). Students’ Needs, Teachers' Support, and Motivation for Doing Homework: A Cross-Sectional Study. Experimental Education, 78, 246267. https://doi.org/10.1080/00220970903292868

Kingery, J. N., Erdley, C. A., \& Marshall, K. C. (2011). Peer Acceptance and Friendship as Predictors of Early Adolescents' Adjustment across the Middle School Transition. Merrill-Palmer Quarterly. Journal of Developmental Psychology, 57, 215-243. https://doi.org/10.1353/mpq.2011.0012

Knesting, K. (2008). Students at Risk for School Dropout: Supporting Their Assistance. Preventing School Failure, 52, 3-10. https://doi.org/10.3200/PSFL.52.4.3-10

Kusurkar. R. A, Croiset, G., \& Ten Cate, T. J. (2011). Twelve Tips to Stimulate Intrinsic Motivation in Students through Autonomy-Supportive Classroom Teaching Derived from Self-Determination Theory. Medical Teacher, 33, 978-982. https://doi.org/10.3109/0142159X.2011.599896

Lamb, S., Dwyer, P., \& Wynn, J. (2000). Non-Completion of School in Australia. LSAY Research Report No. 16, Australian Council for Educational Research.

Lamb, S., Walstab, A., Teese, R., Vickers, M., \& Rumberger, R. (2004). Staying on at School: Improving Student Retention in Australia, Centre for Post-Compulsory Education and Lifelong Learning. The University of Melbourne. http://www.curriculum.edu.au

Latif, A., Choudhary A. I., \& Hammayun, A. A. (2015) Economic Effects of Student Dropouts: A Comparative Study. Journal of Global Economics, 3, Article ID: 1000137.

Legault, L., Pelletier, L., \& Green-Demers, I. (2006). Why Do High School Students Lack Motivation in the Classroom? Toward an Understanding of Academic Amotivation and the Role of Social Support. Journal of Educational Psychology, 98, 567-582. https://doi.org/10.1037/0022-0663.98.3.567

Little, A. W., Indika, H. N. U. \& Rolleston, C. (2011). Access, Attendance, and Achievement in Rural Schools in Sri Lanka. CREATE Pathways to Access. Research Monograph No. 73, The Institute of Education, University of London. http://www.create-rpc.org 
Liyanage, I. K. (2013). Education System of Sri Lanka: Strengths and Weaknesses. (pp. 116140). Institute of Developing Economies, Japan External Trade Organization. http://www.ide.go.jp/library/Japanese/Publish/Reports/InterimReport/2013/pdf/C02_c $\underline{\text { h7.pdf }}$

Martin, A. J. (2014). The Motivation and Engagement Scale-Junior School (14th ed.). Lifelong Achievement Group.

Ministry of Education (2011). Annual Report. Ministry of Education.

Ministry of Education (2014). Annual Report. Ministry of Education.

Ministry of Education, UNICEF, and MG Consultants (2009). Study on Children Who Have Dropped Out of School with Emphasis on Schools with High Dropout Rates. Ministry of Education.

National Research Council (2004). Engaging Schools: Fostering High School Students' Motivation to Learn. The National Academies Press.

Nelson, R. M., \& DeBacker, T. K. (2008). Achievement Motivation in Adolescents: The Role of Peer Climate and Best Friends. The Journal of Experimental Education, 76, 170-189. https://doi.org/10.3200/JEXE.76.2.170-190

Niemiec, C. P., \& Ryan, R. M. (2009). Autonomy, Competence, and Relatedness in the Classroom: Applying Self-Determination Theory to Educational Practice. Theory and Research in Education, 7, 133-144. https://doi.org/10.1177/1477878509104318

Oginsky, T. (2003). Supporting the Development of Intrinsic Motivation in the Middle School Classrooms. Mary Grove College. https://eric.ed.gov

Patrick, H., Ryan, A. M., \& Kaplan, A. (2007). Early Adolescents' Perceptions of the Classroom Social Environment, Motivational Beliefs, and Engagement. Journal of Educational Psychology, 99, 83-98. https://doi.org/10.1037/0022-0663.99.1.83

Perera, M. A. N. R. (2006). A Sociological Perspective of Educational Problems in Sri Lanka: Case in Colombo. In R. S. Sandhu, J. Sandhu, \& B. Arora (Eds.), Urban Poverty in Developing Countries: Issues and Strategies for Sustainable Cities (pp. 110-120). BOOKWELL.

Perera, M. A. N. R. (2011). School Dropouts in Sri Lanka: A Sociological Analysis. First International Research Conference on Humanities and Social Sciences, University of Sri Jayewardenepura.

Pitman, J., \& Herschell, P. (2002). The Senior Certificate: A New Deal. Department of Education, Queensland. http://www.education.unimelb.edu.au

Reeve, J., \& Jang, H. (2006). What Teachers Say and Do to Support Students' Autonomy during a Learning Activity. Journal of Educational Psychology, 98, 209-218. https://doi.org/10.1037/0022-0663.98.1.209

Reeve, J., Deci, E., \& Ryan, R. (2004). Self-Determination Theory: A Dialectical Framework for Understanding Socio-Cultural Influences on Student Motivation. In D. M. McInerney, \& S. Van Etten (Series and Vol. Eds.) Research on Socio-Cultural Influences on Motivation and Learning (Vol. 4, Big theories revisited, pp. 31-59). Information Age Publishing.

Rhodes, J., Grossman, J., \& Resch, N. (2000). Agents of Change: Pathways through Which Mentoring Relationships Influence Adolescents' Academic Adjustment. Child Development, 71, 1662-1671. https://doi.org/10.1111/1467-8624.00256

Roorda, D. L., Koomen, H. M., Spilt, J. L., \& Oort, F. J. (2011). The Influence of Affective Teacher-Student Relationships on Students' School Engagement and Achievement a Meta-Analytic Approach. Review of Educational Research, 81, 493-529.

https://doi.org/10.3102/0034654311421793 
Roth, G., Assor, A., Kanat-Maymon, Y., \& Kaplan, H. (2007). Autonomous Motivation for Teaching: How Self-Determined Teaching May Lead to Self-Determined Learning. Journal of Educational Psychology, 99, Issue 4, 761-774. https://doi.org/10.1037/0022-0663.99.4.761

Ryan, R. M., \& Deci, E. L. (2000a). Self-Determination Theory and the Facilitation of Intrinsic Motivation, Social Development, and Well-Being. American Psychologist, 55, 68-78. https://doi.org/10.1037/0003-066X.55.1.68

Ryan, R. M., \& Deci, E. L. (2000b). Intrinsic and Extrinsic Motivations: Classic Definitions and New Directions. Contemporary Educational Psychology, 25, 54-67. https://doi.org/10.1006/ceps.1999.1020

Ryan, R. M., \& Patrick, H. (2001). The Classroom Social Environment and Changes in Adolescents' Motivation and Engagement during Middle School. American Educational Research Journal, 38, 437-460. https://doi.org/10.3102/00028312038002437

Ryan, R. M., Williams, G. C., Patrick, H., \& Deci, E. L. (2009). Self-Determination Theory and Physical Activity: The Dynamics of Motivation in Development and Wellness. Hellenic Journal of Psychology, 6, 107-124.

https://www.researchgate.net/publication/264531505

Sagor, R. (2003). Motivating Students and Teachers in an Era of Standards. Association for Supervision and Curriculum Development.

Salinas-Jimenez, M., Artes, J., \& Salinas-Jimenez, J. (2010). Income, Motivation, and Satisfaction with Life: An Empirical Analysis. Journal of Happiness Studies, 11, 779-793. https://doi.org/10.1007/s10902-010-9185-y

Schmakel, P. K. (2008). Early Adolescents' Perspectives on Motivation and Achievement in Academics. Urban Education, 43, 723-749. https://doi.org/10.1177/0042085907311831

Stroet, K., Opdenakker, M., \& Minnaert, A. (2013). Effects of Need Supportive Teaching on Early Adolescents' Motivation and Engagement: A Review of the Literature. Educational Research Review, 9, 65-87. https://doi.org/10.1016/j.edurev.2012.11.003

Suarez, D. (2007). When Students Choose the Challenge. Educational Leadership, 65, 6065. http://www.ascd.org

Symonds, J., \& Galton, M. (2014). Moving to the Next School at Age 10 - 14 Years: An International Review of Psychological Development at School Transition. Review of Education, 2, 1-27. https://doi.org/10.1002/rev3.3021

Symonds, J., \& Hargreaves, L. (2016). Emotional and Motivational Engagement at School Transition: A Qualitative Stage Environment Fit Study. Journal of Early Adolescence, 36, 54-85. https://doi.org/10.1177/0272431614556348

Tsai, Y., Kunter, M., Lüdtke, O., Trautwein, U., \& Ryan, R. M. (2008) What Makes Lessons Interesting? The Role of Situational and Individual Factors in Three School Subjects. Journal of Educational Psychology, 100, 460-472. https://doi.org/10.1037/0022-0663.100.2.460

United Nations (2014). Millennium Development Goals Country Report. Sri Lanka. http://lk.one.un.org

Vansteenkiste, M., Lens, W., \& Deci E. L. (2006). Intrinsic versus Extrinsic Goal Contents in Self-Determination Theory: Another Look at the Quality of Academic Motivation. Educational Psychologist, 41, 19-31. https://doi.org/10.1207/s15326985ep4101 4

Vansteenkiste, M., Simons, J., Lens, W., Sheldon, K. M., \& Deci, E. L. (2004). Motivating Learning, Performance, and Persistence: The Synergistic Effects of Intrinsic Goal Contents and Autonomy-Supportive Contexts. Journal of Personality and Social Psychology, 87, 246-260. https://doi.org/10.1037/0022-3514.87.2.246 
Wagle, D. (2012). Dropout of Children from Schools in Nepal. Master Thesis, Norwegian University of Science and Technology.

Walker, C., Greene, B. \& Mansell, R. (2006). Identification with Academics, Intrinsic/Extrinsic Motivation, and Self-Efficacy as Predictors of Cognitive Engagement. Learning \& Individual Differences, 16, 1-12. https://doi.org/10.1016/j.lindif.2005.06.004

Wang, M. T., \& Eccles, J. S. (2013). School Context, Achievement Motivation, and Academic Engagement: A Longitudinal Study of School Engagement Using a Multidimensional Perspective. Learning and Instruction, 28, 12-23.

https://doi.org/10.1016/j.learninstruc.2013.04.002

Williams, J. (2000). Student Engagement at School: A Sense of Belonging and Participation. Results from PISA 2000, OECD.

Williams, K. C., \& Williams, C. C. (2011). Five Key Ingredients for Improving Student Motivation. Research in Higher Education Journal, 12, 1-23. http://www.aabri.com

Wilson, L. (2007). Great American Schools: The Power of Culture and Passion. Educational Horizons, 86, 35-44. https://files.eric.ed.gov/fulltext/EJ776907.pdf

Wlodkowski, R. J. (1999). Enhancing Adult Motivation to Learn. Jossey Bass Publishers.

World Bank (2005). Treasures of the Educational System in Sri Lanka: Restoring Performance, Expanding Opportunities, and Enhancing Prospects. The World Bank. http://www.unicef.org

World Bank (2011). Transforming School Education in Sri Lanka: From Cut Stones to Polished Jewels. World Bank Sri Lanka Country Office. 


\section{Appendix A-1: Harsh Punishments}

Science teacher punishes us. As soon as we give a wrong answer, he hits us. I don't like learning science at all. Student (S) 1

I'm punished by teachers in front of my friends. So, I'm so upset. I hate learning mathematics. S 4

Some teachers punish us for unfinished work. So, I don't like them. When I remember those things, I feel so worried. S 12

I do not like learning English. The teacher looks at me very angry always. Some teachers punish us for not completing homework. S 20

I like Tamil teacher. He is not like other teachers who punish us always. I come to school because of him. He never punishes me. He encourages me in learning. $\mathrm{S} 7$

When I ask something difficult for me to understand, they always scold us. S 4 Some teachers do not smile with us. I'm afraid to look at their faces.

I do not like male teachers. They blame us. S 3

Most of my teachers are mean. S 21

\section{Appendix A-2: Inadequate Encouragement}

Sometimes my teachers encourage me when I am good at work. S 22

When I was given an appreciation in front of others, I feel very happy ... But I do not get those. S 6

Our teachers do not encourage us. They do not encourage our attempts. S 14

When I try to give an answer, some of my teachers do not allow me to do that. They think that I always give wrong answers. S 4

If our teachers appreciate us, we are very happy ... We do not want to get blamed at all the times. S 15

Sometimes I do some parts of my homework as I can. Then teachers blame me for not completing tasks. So, I am so worried. S 9

\section{Appendix A-3: Un-Engaging Teaching}

Our teachers' teaching is so boring. They do not use new activities to teach. S 9

We always have the same kind of teaching. $\mathrm{S} 1$

I would like to have different types of lessons. S 3

I would like to use our skills when we learn. S 21

I would like to learn by doing something, but no opportunities available. S 14

It seems that the teachers use traditional teaching methods and techniques such as the lecture or the "talk and chalk" method.

I would like to do experiment while learn. S 12

I would like to learn using computers. S 2

I like to do activities using different learning aids. S 4

We do not like to just listen to the teachers, we like to see new things and learn. S 19 


\section{Appendix A-4: Unfriendly Teaching-Learning Environment}

Primary teachers were very kind. They didn't punish us. S 1

We didn't have much to do in primary classes. Now we have lots of subjects to learn and lots of homework to do. Different teachers teach us. So, now we are so confused in learning. $S 11$

In primary years, teachers knew us individually, and now some teachers can't remember our names even. $\mathrm{S} 2$

According to Tamil-medium students:

Some teachers treat well for clever students only. S 7

I sense that some teachers don't like me. They think that I'm a stupid. S 12

The teacher does not seem to care if I do not pay attention anyway. S 9

Teachers do not care about me. S 3

\section{Appendix A-5: Influence of Peers}

I don't like classmates. They hate me always. They always tell my faults to teachers. S 12

There are some classmates who perform well in our classroom in difficult subjects. But they don't like us to help. They hate us always. S 14

My friends do not like to learn. So, I also don't like to learn. They always talk about earning money. $S 1$

My friends always overstress about everything. I get stressed about it and can be emotional. S 3

My classmates are also not motivated in learning. There is not any competition in our classroom. So, I'm also unmotivated. S 10

Hanging out with the wrong friends affects my grades. They try to bring me down. S 15

\section{Appendix A-6: Inadequate Quality Learning Activities}

I like learning science. But there are not any activities that we can do. S 11

I like doing activities. We have activities only in science. They are also very limited. S 3

In primary years we did lots of activities. Now not like that ... Learning is so boring. $\mathrm{S} 12$

Nothing to do with ourselves, the teachers teach everything; we have to just listen to them. S 14

I do not like to learn by listening. I want to do something. S 4

The teachers spend too much time talking or reviewing a subject. S 15

We are not being allowed to participate in class or ask questions. S 2

The following are examples of a common criticism expressed by both genders:

We want to learn by doing something. But we don't have such activities in our classrooms mostly. So, we feel bored to learn. S19

Sometimes I don't like to listen to teachers. Listening is boring. I don't understand what they teach specially in English, science, and mathematics. S 17 
Always teachers ask to do the exercise in the textbooks. I hate doing that always. No difference. Always doing the same thing is boring. S 9

Always we have only one type of assignments. S 13

We don't have enough opportunities to discuss within the classroom; always teacher ask questions from clever students. S 7

\section{Appendix A-7: Difficult Subject Matters}

I hate learning science, mathematics, and English. S 3

When I have mathematics and English double periods, I don't come to school. S 2

Mathematics and English are too hard for me. I don't like to learn those. S 21

Always I get low marks for mathematics. So, I hate learning mathematics. S 8

I didn't come for last term-end test for mathematics and English. I was blamed by teachers. But those subjects are really a pressure for me. S 11

Learning those subjects is not interesting for me. They are too hard. S 22

\section{Appendix A-8: Difficult and Excessive Homework}

In primary years, we didn't have much homework to do. But now we have lots of homework to do. S 20

I don't know how to do some tasks, particularly in mathematics and English. $S$ 13

If I ask from teacher repeatedly, he blames or punishes me. So, I hate doing homework. S 3

When I don't complete homework, I don't like to come to school. S 9

In the same day we have to do homework related to three subjects. So, we are unable to complete them on time. S 17

\section{Appendix A-9: Regular Tests}

In our classroom, we have monthly tests for all the subjects. So, we feel confused. S 18

We always have tests and I get low marks for them. So, I do not like to come for tests. S 8

For term tests I get low marks for all the subjects. I hate having so many tests within one year. S 6

When teachers tell the individual marks of the students in front of others, I feel embarrassed due to my low marks. S 11

\section{Appendix A-10: Inadequate Classroom Resources}

There are four classrooms located in the same building without partitioning therefore our classroom is too much noisy; so, very difficult to concentrate on learning. $S 2$

We don't have sufficient chairs or desks. S 8

We have very short desks and chairs; they are very inconvenient. S 7 
We don't have a proper blackboard in our classroom. S 15

When it rains our classroom gets wet. So, during that day we are unable to learn. S 14

Our classroom floor is damaged, so it is so hard to learn. S 16

\section{Appendix A-11: Inadequate Quality Teaching-Learning Resources}

We have never seen a computer in our school. S 4

Even though our school has some computers, we are not allowed to use them. S 6

We don't have a playground. We like to do sports. But we don't have sports equipment. S 9

We do not have musical instruments in our school. S 5

We would like to read books, but there is no library in our school. S 8 